\title{
Social Intelligence and Effective Service Delivery in Public Secondary Schools, Akwa Ibom State, Nigeria
}

\author{
Ekanem, E. E. ${ }^{1} \quad$ Udofe, A. P. ${ }^{2} \quad$ Evans, G. F. ${ }^{3}$ \\ 1.Department of Curriculum Studies, Educational Management and Planning, University of Uyo \\ 2.Department of General Studies, Maritime Academy of Nigeria, Akwa Ibom State \\ 3.Department of Educational Foundations, Akwa Ibom State College of Education, Afaha Nsit
}

\begin{abstract}
In every competitive market, effective service delivery is needed to stay afloat. In consideration of the numbers of secondary schools springing up in recent times, it was necessary to investigate effective service delivery as predicted by social intelligence of Management in using secondary schools in Akwa Ibom State. The Ex-post facto design was adopted for the study. The study population of 2,583 staff at Management cadre was used, from which a sample size of 537 was selected using multistage sampling procedure. The instruments were structured questionnaire christened management social intelligence questionnaire (MSI) and effective service delivery (ESD). The reliabilities of the instruments (MSI and ESD) were tested using the Cronbach Alpha statistical tool, which yielded correlation coefficients of 0.75 and 0.83 respectively. Data obtained from 537 Management staff of secondary schools in the study area were analysed using linear regression. Results revealed that Management social intelligence: interpersonal relationship, situational control, and self-judgement significantly predict leadership's effective service delivery in public secondary schools in Akwa Ibom State. Therefore, it was recommended that the Ministry of Education and State's Secondary Education Board should pay close attention to Management social intelligence in public secondary schools to ensure continuous patronage of this sector.
\end{abstract}

Keywords: Social Intelligence, Service Delivery, Management, Public School and

DOI: $10.7176 / \mathrm{JEP} / 11-8-16$

Publication date:March $31^{\text {st }} 2020$

\subsection{Introduction}

In a highly competitive market such as academic institutions, service-based operations need to be capitalized for any organization to stand-out among competitors. This can only be achieved through effective service delivery. Effective service delivery is vital to service management and involves doing the right thing at the right time and in the right manner. Therefore, effective service delivery should not stop with customers but extends more importantly to the internal staff members. It is worthy of note that human relation is complex, and demands both natural and acquired skills at every point in time. People are born with intelligence; hence, their quotients differ from persons to persons. However, social intelligence is acquired through training (learning) and experiences (Goleman, 2008; Saiti, 2014; Ogden and Germinario, 2014; Anderson, 2010; Bryrant, 2016).

In the school setting, the Principal is the Administrator and it is incumbent on him to coordinate the physical and psychological activities of students, teachers, visitors as well as the host communities. Administration involves series of activities, with the aim of driving effective service delivery. This can only be achieved through social intelligence (SI) .Riggio (2016), sees social intelligence as the ability to understand and manage humans so that they can act wisely in human relations. In the views of Gynanduru and Kumar (2007); Hsin-Yi (2014) and Cote (2015), social intelligence is the ability to get along with others, and to get them to cooperate with you. Ebrahimpoor, Zahed and Elyasi (2013), studied the relationship between social intelligence and organizational performance: a case study of Ardabil Managers. The study investigated the relationship between social intelligence, skills, social skills, and social information processing and Managers' effectiveness. Findings revealed that interpersonal skill (social skill) significantly relates with Managers' effectiveness and performance. This supported the earlier findings by Gynanduru and Kumar (2007); Kosnic and Beck (2011).

It has been observed that secondary schools' Administrators seem not to exhibit emotional maturity because of reports on incessant conflicts among Principals and their subordinates in school organisation (Yukl, 2008). In a study on administrative strategy and effectiveness reported by Usabor (2014), administrators that apply listening skills in order to communicate, staff motivation, show sympathy and empathy in their everyday administration ,achieved better than those that discern, scold, abuse and see nothing good in their staff. In addition, researchers such as, Riggio (2008); Nwanze (2008); Ebrahimpoor, Zahed and Elyasi, (2013); Saiti (2014); JohnAfrica (2014), have shown that social intelligence improves organisational performance. The lack of social intelligence skills (such as empathy, listening, communication, interpersonal relationships and self-judgement) could be the reason for Administrators' use of verbal abuse, threats and force to gain subordinates' compliance and respect. This could be the reasons for poor service delivery witnessed in various public and private establishments. Unfortunately, none of these studies was carried out in Akwa Ibom State, despite the numbers of schools. Therefore, the fundamental problem that this study intends to address is administrators' social intelligence 
(SI) and effective service delivery in Akwa Ibom State's public secondary schools from the stand point of interpersonal relationship.

\subsection{Purpose of the Study}

The purpose of this study was to examine the extent to which social intelligence could predict effective service delivery among public secondary school administrators in Akwa Ibom State. In specific terms, this study determined:

1. the extent to which secondary school management's interpersonal relationship could predict effective service delivery;

2. the extent to which secondary school management's situational control ability could predict effective service delivery; and

3. the extent to which secondary school management's self-judgement could predict effective service delivery.

The study therefore hypothesized that:

1. Management's interpersonal relationship does not significantly predict effective service delivery;

2. Management's situational control ability does not significantly predict effective service delivery; and

3. Management's self- judgement does not significantly predict effective service delivery.

\subsection{Methodology \\ 3.1 Research Design}

The ex-post facto design called causal comparative design was used for the study. This design was necessary because the researchers had no direct control over the variables. The nature of this study suggests that the variables; social intelligence and effective service delivery, had already existed and therefore, no attempt was made to manipulate the variables (Uyanga and Etudor-Eyo, 2015). The researcher found this design appropriate for the study as it attempts to find out the existing influence of the independent variable (Management social intelligence) on the dependent variable (Effective service delivery).

\subsection{Area of the Study}

This research was conducted in Akwa Ibom State, Nigeria. The State is located in the South-south geo-political Zone of Nigeria and lies between $4^{\circ} 32^{\prime} \mathrm{N}$ and $5^{\circ} 33^{\prime} \mathrm{N}$, and longitudes $7^{\circ} 25^{\prime} \mathrm{E}$ and $8^{\circ} 25^{\prime} \mathrm{E}$. It has a population of about 3,920,208 people (National Census Commission 2006). The State covers a land mass of 8,413 square kilometres and is blessed with an ocean front which spans 129 kilometres. Akwa Ibom state is made up of 31 Local Government Areas with three major ethnic groups -Ibibio, Annang and Oron. The State is bordered to the east by Cross Rivers State, to the west by Rivers and Abia States and to the south by the Atlantic Ocean. Educationally, the state has about 234 secondary school with sizable number located in the rural areas (Akwa Ibom State Secondary Education Board, 2017/2018 records). The State hosts many Federal and State tertiary institutions such as the University of Uyo, Akwa Ibom State University, Maritime Academy of Nigeria, Akwa Ibom State College of Education, Akwa Ibom State Polytechnic, Schools of Nursing, School of Basic Studies, College of Arts and Science. Others are Obong University, Ritman University, Uyo City Polytechnic, Apex Polytechnic, Heritage Polytechnic. The choice of this study area is based on the fast growing academic institutions which require Administrators to drive for effective service delivery.

\subsection{Population of the Study}

The population of this study comprised teachers in the rank equivalent to that of vice principals, and principals in the 235 public secondary schools in Akwa Ibom State. There are 1,683 teachers with same rank as vice principals, 705 vice principals and 235 principals in Akwa Ibom State for 2017/2018 school years. This gave a total population of 2,583 (Akwa Ibom State Secondary Education Board Monograph, 2018).

\subsection{Sample and Sampling Technique}

The sample of the study consisted of 537 management staff (high cadre teachers, vice principals and principals) in Akwa Ibom State public secondary schools. This sample was selected using a multi-staged sampling technique from the three Senatorial Districts in Akwa Ibom State. The districts were clustered into three areas: Uyo, Eket and Ikot Ekpene. A total of 10 schools were randomly selected from each of the three senatorial districts, through hat and draw method. Therefore, a total of 30 schools were used for the study. The researcher used purposive sampling technique to select 18 teachers (at the rank of vice principal) from 29 schools and 15 school Principals (Administrators) from the $30^{\text {th }}$ school, since Administrators were not up to 18 . The Principals and the high ranking teachers constituted Management used for the study, and this gave a total sample size of 537 . 


\subsection{Instrumentation}

Two research instruments, Management social intelligence questionnaire (MSI) and effective service delivery questionnaire (ESD), were designed and used for data collection. The Management social intelligence questionnaire (MSI) contained sections A and B. Section A is made up of demographic information on respondents while section B, contains 42 items on a four point scale and was used to collect data on Management social intelligence. The 42 items were divided into 3 sub-sections to obtain data on interpersonal relationship, situational control and self-judgement. The effective service delivery questionnaire (ESD) is a 40 items' structured questions, which collect data on a four point rating scale indicating respondents' opinion.

The instruments' reliabilities were determined using data obtained from 20 respondents who were not part of the main study. The reliabilities of the instruments were determined by subjecting obtained data to Cronbach alpha reliability analysis, which produced reliability coefficient of 0.730 for MSI and 0.842 for ESD.

\subsection{Statistical Treatment of Data}

The data generated from questionnaires were analysed using simple linear regression. The coefficient of determination $\mathrm{R}^{2}$ value of the simple linear regression and the F-value of the simple linear regression at 0.05 level of significance were interpreted. The extent of prediction was determined by the strength of the relationship between the social intelligence and effective service delivery employing the following rules:

when $\mathrm{R}^{2}=0 \quad$ no relationship exist

$\mathrm{R}$ lies between positive or negative 0.1 and 0.3 (weak relationship)

$\mathrm{R}$ lies between positive or negative 0.4 and 0.6 (moderate relationship)

$\mathrm{R}$ lies between positive or negative 0.7 and 1.0 (strong relationship)

$\mathrm{R}^{2}$ values (coefficient of determination) lie between .001 and 1.00 , when multiplied by 100 . This gives the percentage of variation between dependent and independent variables under study. It means that, the smaller the coefficient of determination, the smaller the percentage of variation, and the weaker the relationship between the dependent and independent variables and vice versa.

\subsection{Results and Discussion}

4.1 The extent to which management's interpersonal relationship predicts effective service delivery

Table 1: Summary of simple linear regression analysis for the prediction of effective service delivery by management's interpersonal relationship in public secondary schools in Akwa Ibom State $(\mathrm{N}=537)$

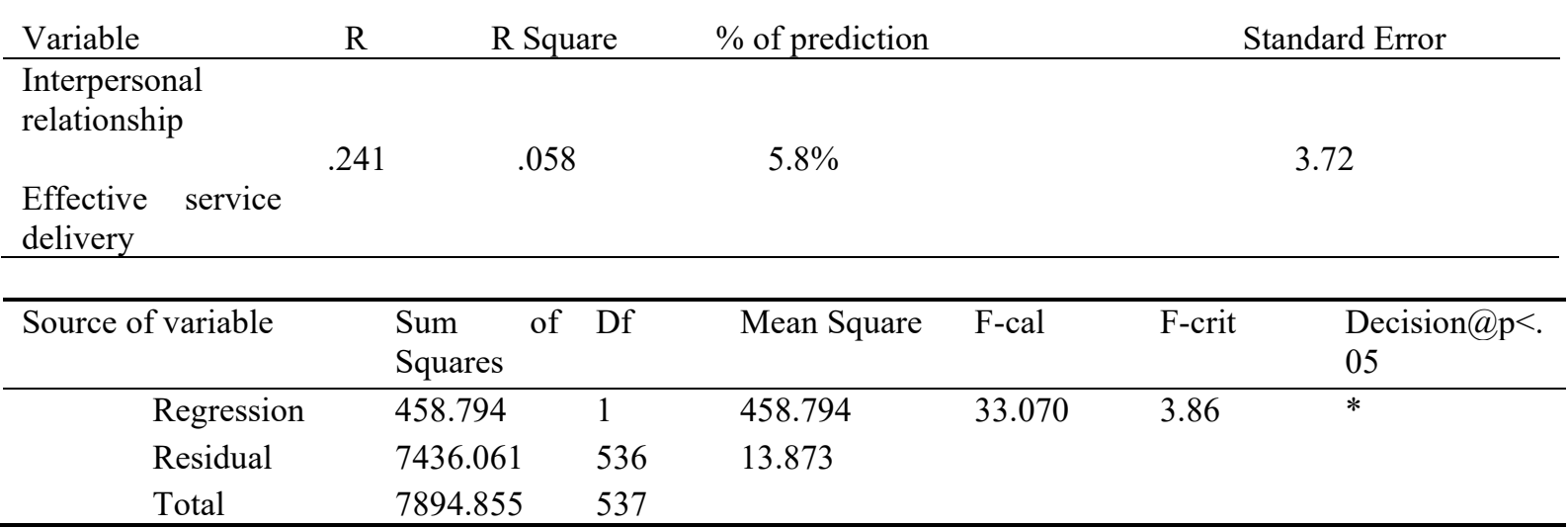

The entries in upper part Table 1 report the extent to which interpersonal relationship predicts effective service delivery in all secondary schools in Akwa Ibom State. The correlation coefficient (R) of .241 obtained for the linear correlation between interpersonal relationships and effective service delivery is low. This low value shows a weak but positive correlation. Also, the extent of prediction of effective service delivery by interpersonal relationship is indicated by the value of coefficient of determination $\mathrm{R}^{2}(.058)$. This implies that interpersonal relationship accounts for $5.8 \%$ of the variance in effective service delivery. The low value of $\mathrm{R}^{2}$ shows a small percentage of variation. Therefore, it seems that interpersonal relationship lowly predicts effective service delivery of management in public secondary schools in Akwa Ibom State.

The lower part of Table 1 shows the computed F-value of 33.070 exceeded the critical value of 3.86 at the degree of freedom of 1 and 536 and 0.05 significant level. The null hypothesis which states that interpersonal relationship does not significantly predict effective service delivery in Akwa Ibom State secondary education is rejected. This implies that effective service delivery is significantly predicted by interpersonal relationship of public secondary schools' management. 
4.2 The extent to which management's situational control ability predicts effective service delivery is not significant

The entries in Table 2 reports the extent to which situational control ability predicts effective service delivery in all secondary schools in Akwa Ibom. The correlation coefficient (R) of 0.382 is the linear correlation between situational control and effective service delivery. The low value shows a weak but positive correlation. Also, the extent of prediction is shown by the value of coefficient of determination $\mathrm{R}^{2}(0.146)$.

Table 2: Summary of simple linear regression analysis for the prediction of effective service delivery by management's situational control in public secondary schools in Akwa Ibom State $(\mathrm{N}=537)$

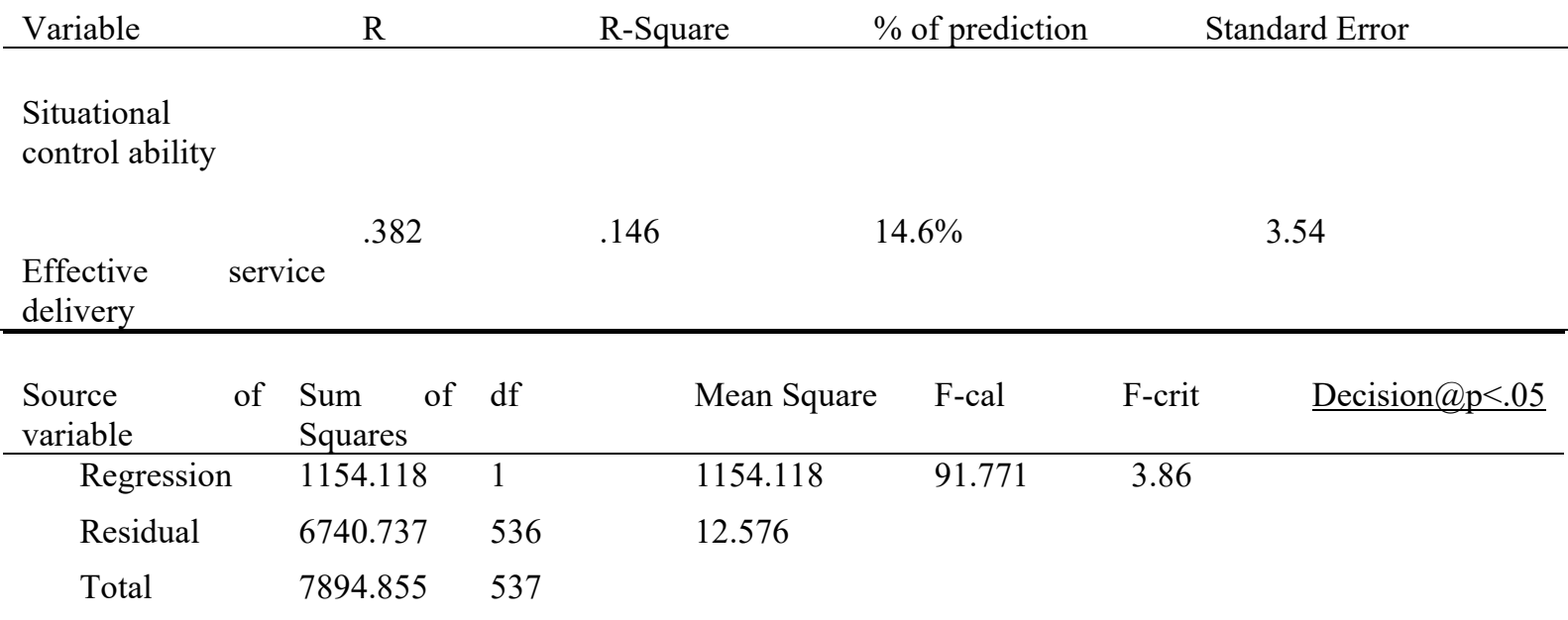

*Significant at .05

This implies that, situational control ability accounts for $14.6 \%$ of the variance in effective service delivery. The low value of $\mathrm{R}^{2}$ shows a small percentage of variation. Therefore, situational control appears to lowly predict effective service delivery of management in public secondary schools in Akwa Ibom State.

As shown on the lower part of Table 2, the computed F-value of 91.771 exceeded the critical value of 3.86 at the degree of freedom of 1 and 536 and 0.05 significant level. The null hypothesis which states that situational control ability does not significantly predict effective service delivery in Akwa Ibom State secondary education is rejected; whereas, the alternate hypothesis which state that situational control ability predicts effective service delivery in Akwa Ibom State secondary education significantly is accepted. This implies that effective service delivery in Akwa Ibom State is significantly predicted by situational control ability of school management.

4.3 The extent to which management's interpersonal relationship predicts effective service delivery is not significant in Akwa Ibom State.

Table 3: Summary of simple linear regression analysis for the prediction of effective service delivery by management's self- judgement in public secondary schools in Akwa Ibom State $(\mathrm{N}=537)$

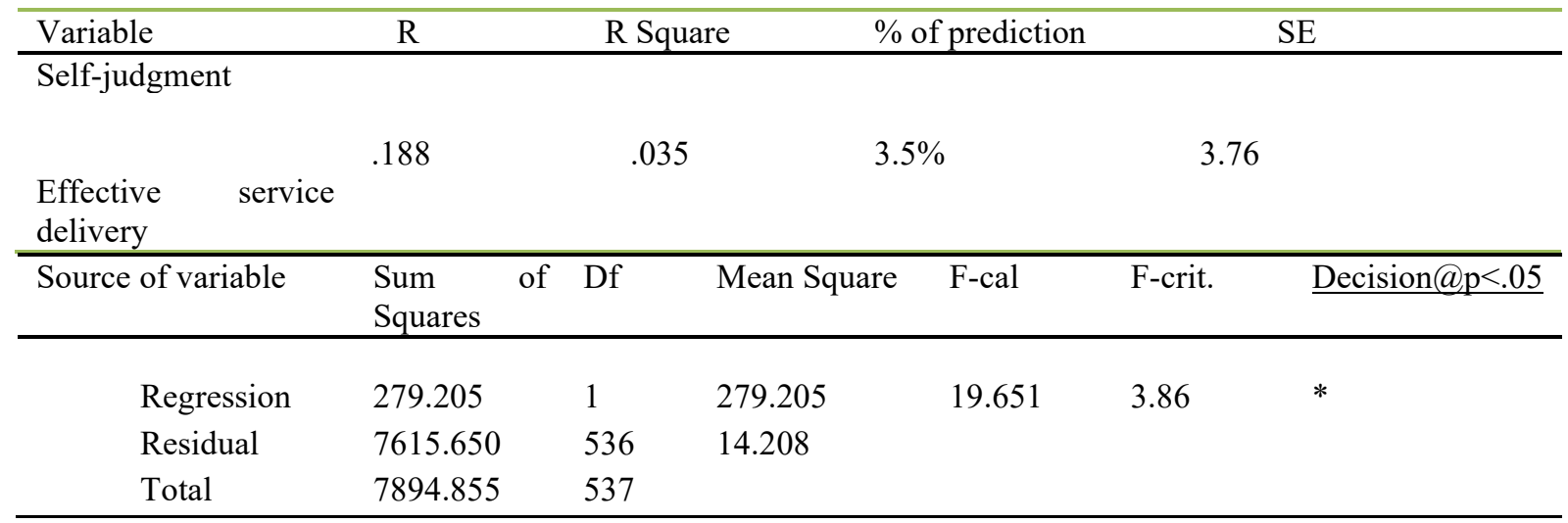

*Significant at .05

The entries in Table 3 reports the extent to which self- judgement effective service delivery in all secondary schools in Akwa Ibom. The correlation coefficient (R) of .188 is the linear correlation between self- judgement and effective service delivery. The low value shows a weak but positive correlation. Also, the prediction is shown by the value of coefficient of determination $\mathrm{R}^{2}(.035)$. This implies that self- judgement accounts for $3.5 \%$ of the 
variance in effective service delivery. The low value of $\mathrm{R}^{2}$ shows a small percentage of variation. Therefore, the extent to which self-judgement predicts effective service delivery of management in public secondary schools in Akwa Ibom State is seemingly low. Table 3 further indicates that, computed F-value of 19.651 exceeded the critical value of 3.86 at the degree of freedom of 1 and 536 and 0.05 significant level. The null hypothesis which states that self-judgment does not significantly predict effective service delivery in Akwa Ibom State Secondary school was rejected; whereas, the alternate hypothesis which states that self-judgment predicts effective service delivery in Akwa Ibom State secondary education significantly is accepted. This implies that effective service delivery in Akwa Ibom State public secondary schools was significantly predicted by self-judgment of school management.

The study revealed that interpersonal relationship significantly predicts effective service delivery by public secondary school, and it accounts for $5.8 \%$ of the variance. The inferential statistics further indicates that, the extent to which effective service delivery by public secondary schools is predicted by interpersonal relationship is low. This implies that effective service delivery by public school management is weakly predicted by interpersonal relationship. The weak but positive relationship between interpersonal relationship and effective service delivery indicates that strong interpersonal relationship would promote effective service delivery. This finding is in line with the findings of Gynanduru and Kumar (2007); Kosnic and Beck (2011) and Ebrahimpoor, Zahed and Elyasi (2013).

Findings of the study also revealed that, situational control significantly predicts effective service delivery of public secondary schools, and accounting for $14.6 \%$ of the variance. The inferential statistics further indicates that, the extent to which effective service delivery in public secondary schools is predicted by situational control is low. This implies that effective service delivery of public secondary school is weakly predicted by situational control. The reason for this outcome could be that Management of public secondary schools do not acquire enough training on situational control such as: time and situational awareness and stress management. The finding was also in consonant with Duze (2012); Ogden and Germinario (2014) and Bryrant, (2016). They reported of significant effect of situational control ability on effective service delivery.

The study also revealed that self-judgement significantly predicts effective service delivery of public secondary school, which accounts for $3.5 \%$ of the variance. The inferential statistics further indicates that, the extent to which effective service delivery of management in Akwa Ibom state public secondary schools is predicted by self-judgement is low. This implies that effective service delivery of Management in Akwa Ibom state public schools is weakly predicted by self-judgement. This outcome could be that Management of public secondary schools do not appraise their performances enough so as to improve upon them. It also indicates weak accountability. This finding could be as a result of poor monitoring and evaluation of management of public secondary schools. This finding is supported by the findings of Ryan and Deci (2000); Cooper (2010); Anderson (2010) and Suzette (2014). They reported that, self-judgement is a strong determinant for effective service delivery.

\subsection{Conclusions}

This study was conducted to determine how social intelligence variables could predict management's effective service delivery in public secondary schools in Akwa Ibom State. The study considered the following social intelligent sub-variables: interpersonal relationship, situational control and self-judgment. These indicators were investigated to determine the strength of the relationship or prediction of effective service delivery among Management in Akwa Ibom State public secondary schools. Several authors were consulted as acknowledged in the references. It was concluded based on findings that social intelligence predicts Management's effective service delivery in public secondary schools of Akwa Ibom State. Principals should be encouraged to acquire these skills through workshops and seminars sponsored by the government, to improve effective service delivery and reduce chaos and conflict in school organisation.

\section{References}

Anderson, C. (2010). Attitude of in-service and pre-service primary school teachers. Journal of Education Psychology, 2 (1): 23-28.

Bryrant, D. (2016). Components of emotional intelligence as it relates to sales performance. Available at: http//:www.sciencedirect.com/ science/article. Retrieved 14 ${ }^{\text {th }}$ April, 2015.

Cote, S. E. (2015). A social interaction model of regulation on work strain. Academy of Management Review, 30: $509-530$

Duze, C. O. (2012). Comparative analysis of principals' management strategy in public and private schools in Anambra state of Nigeria. An international Journal of Arts and Humanities, 1 (1): 239 - 256.

Ebrahimpoor, H., Zahed, A. and Elyasi, A. (2013). Social intelligence and organizational performance: A case study of Ardabil managers. International Journal of Organiszational Leadership, 2 (1), 1-10.

Goleman, D. (2008). Primal Leadership: Learning to Lead with Emotional intelligence. Boston: Harvard Business School's Press.

Gynanduru, M. and Kumar, R. (2007).A Comparative study of teacher effectiveness, general intelligence and 
creativity of public and private school teachers trained through the formal and distance modes. Indian Journal of Distance Education, 9: 61-75.

Hsin-YI, B. (2014).Early Teacher-Child relationships and the trajectory of children's school outcomes through Eighth grade child development. Academy Management Review.72, 625-638.

John-Africa, G. D.(2014).Emotional Intelligence: Why It Can Matter More Than IQ. 199. New York: Bantam Books.

Nwanze, J. T. (2008).Students' Learning Attitude - the Nigerian Experience. Port Harcourt: Renaissance Publishers.

Ogden, C.A., Germinario, J. A. (2014).Culture as social control: Corporations, cults, and commitment. Research in Organizational Behaviour, 18: 157-200.

Ryan, R. M., and Deci, E. L. (2000).Self-determination theory and the facilitation of intrinsic motivation social development, and well-being. American Psychologist, 55: 68-78.

Riggio, R. E. (2008). Emotional and social intelligence for effective leadership. An emotional and social approach. Journal of Managerial Psychology, 23 (2) 169 -185.

Saiti, P. E. (2014). The role of school leaders in conflict management. Journal of the British Educational Leadership. 45 (6), 48 - 53.

Usabor, E. E. (2014). School impress system and administrative effectiveness of secondary school principals in Uyo Senatorial District, Akwa Ibom State. Journal of Research in Education, 5 (3), 20 - 24.

Uyanga, R.E. and Etudor-Eyo E. (2015).Research Methodology in Education and Social Science. Uyo: Dorand Publisher.

Yukl, G. (2008). Leadership in an organization. $4^{\text {th }}$ edition. Upper Saddle River, NJ: Pentice Hall. 